\title{
Vacuum Pyrolysis of Waste Vehicle Tyres into Oil Fuel Using A Locally, Fabricated Reactor*
}

\author{
${ }^{1}$ I. Quaicoe, ${ }^{1}$ A. A. Souleymane, ${ }^{1}$ S. K. Kyeremeh, ${ }^{1}$ H. Appiah-Twum, ${ }^{1}$ S.A. Ndur \\ ${ }^{1}$ University of Mine and Technology, P. O. Box 237, Tarkwa
}

Quaicoe, I., Souleymane, A. A., Kyeremeh, S. K, Appiah-Twum, H and Ndur, S. A. (2020), "Vacuum Pyrolysis of Waste Vehicle Tyres into Oil Using A Locally, Fabricated Reactor”, Ghana Mining Journal, Vol. 20, No. 1, pp. $59-65$.

\begin{abstract}
Some countries still face daunting challenges of managing ever-increasing waste generated, especially plastic and waste vehicle tyres. Whilst some developed countries have adopted innovative ways such as catalytic or pyrolytic decomposition processes for energy or fuel generation from these wastes, developing countries like Ghana still dispose off indiscriminately around communities or un-engineered dumpsites. Hence, this study sought to transform waste vehicle tyres into fuel which invariably minimises or eliminates its environmental impact. Particularly, waste vehicle tyres (sourced from dumpsites in Tarkwa, Ghana) were washed, shredded and decomposed via pyrolysis at high temperature range $\left(\sim 450-650{ }^{\circ} \mathrm{C}\right)$ using locally designed and fabricated reactor. The physicochemical properties (such as water content, flashpoint, density, sulphur content, solids and viscosity) of the pyrolysis oil produced were also examined using the American Society for Testing and Materials (ASTM) standards and procedures. The results showed that the viscosity, flashpoint and the density of the pyrolysis oil produced were $0.904 \mathrm{cSt}, 34.5{ }^{\circ} \mathrm{C}$, and $850.6 \mathrm{~kg} / \mathrm{m}^{3}$ (at $15{ }^{\circ} \mathrm{C}$ ), respectively. The sulphur, water and solids/particulates contents were $4340.0 \mathrm{ppm}, 0.8 \mathrm{vol} \%$, and $483,495.5 \mathrm{ppm}$, respectively. It was also observed that the pyrolysis oil obtained appeared as thick, single-phase liquid with dark colour and strong odour at room temperature. Relatively, the properties of pyrolysis oil produced without further treatment did not meet the International specification for diesel fuel, hence its usage would require further treatments such as desulphurisation, decanting, centrifugation and filtration. Overall, the study has demonstrated that the pyrolysis of waste vehicle tyres into fuel provides an alternative method for managing end-of-life vehicle tyres and adding value to waste in general.
\end{abstract}

Keywords: Pyrolysis, Waste Vehicle Tyres, Reactor, Pyrolysis Oil, Biofuel

\section{Introduction}

The pressure to reduce global reliance and consumption rate of fossil fuel as a result of resource scarcity, sustainability and stringent environmental requirements has led to the need to search for alternative energy sources (Cheng and Timilsina, 2011). This has resulted in several studies into renewable energy sources such as solar, wind, hydro, tidal, geothermal and biomass energy/biofuels (Maschio et al., 1992; Barth, 1999; Bridgwater et al., 1999). However, interest in biomass energy or biofuels has been high especially, due to their applicability in the transportation sector (Abbaszaadeh et al., 2012; Mohammadi et al., 2014; Izadi and Rahimnejad, 2014). Thus, biofuels are noted to have unique properties which are relatively similar to the petrobased fuels.

Biofuels can be produced from organic matter, waste or biomass (such as corn, sugar, corn, soybean and sugarcane) (Cheng and Timilsina, 2011; Abbaszaadeh et al., 2012). The main types of biofuels currently produced globally are biodiesel, bioethanol, biobutanol and biogas. These can be classified into first, second, third and fourthgeneration biofuels or may also be grouped into conventional or advanced biofuels depending on the maturity of the technology as well as greenhouse gases (GHG) emission balance (Hamelinck and Faaij, 2006; Luque et al., 2008; Peralta-Yahya et al., 2012).

Biofuels are now regarded as the most promising type of renewable energy source for homes and major industries (e.g., cement, agriculture, mining and transportation). Hence, it is expected to account for at least 25-35\% of the global transport fuels by 2050 (Kartha and Larson, 2000). Despite its potential economic importance, biofuels currently pose serious threats to food security and fertile lands. This is because most of the current biofuels production comes from food crops (such as corn, soybean and sugarcane) cultivated on agricultural lands (Demirbas, 2009; Carriquiry et al., 2011; Timilsina and Shrestha, 2011). In dealing with the issues concerning land use and food security, researchers have focused their attention on biofuel production, especially biodiesel, from organic or crop waste materials.

In general, biodiesels are monoalkyl esters, that can be derived from vegetable oils, animal fat, alcohols of lower molecular weights (e.g., ethanol and methanol), organic waste (e.g., waste vehicle tyres, agro waste) in the presence of catalysts (either basic or acidic catalysts in homogeneous or heterogeneous forms) (Tabatabaei et al., 2011; Sharma et al., 2008). Now, biodiesel is rapidly gaining worldwide attention as a good alternative 
fuel for diesel engines due to its moderate exhaust emissions, sustainability and biodegradability (Sharma et al., 2008). However, little is known of the economic and technical viability of higher generation technologies such as waste-oriented and algal-fuels (Demirbas, 2009; Carriquiry et al., 2011; Timilsina and Shrestha, 2011). Therefore, studies focused on waste-oriented and algal-fuels production from waste such as car tyres, plastic waste is warranted.

Globally, it is estimated that about 1.5 billion tyres are produced yearly, which invariably enters the waste stream representing a major waste and environmental problem due to its complex composition (Williams, 2013; Islam and Nahian, 2016). Vehicle tyres contain long-chain polymers (butadiene, isoprene, and styrene-butadiene) which are cross-linked with sulphur to enhance greater resistance to degradation (Evans and Evans, 2006). Some modern pneumatic tyres comprise synthetic and natural rubber $(50 \%)$, carbon black $(21.5 \%)$, fabric $(5.5 \%)$, metal wire (16.5), chemical constituents (e.g., silica, zinc oxide, sulphur) (1\%) and, other carbon-based materials and additives (7.5\%) (Evans and Evans, 2006). Due to the complex nature of tyres constituents, it is difficult to utilize one disposal method to deal with waste tyres hence pose serious health and environmental threats.

Some of the traditional and modern ways of managing waste vehicle tyres over the years include landfilling, indiscriminate dumping, stockpiling, open-air burning, incineration, crumbing, remoulding/recycling as well as energy recovery through pyrolysis (Swain, 2013; Galvagno and Cornacchia, 2002). It is worth noting that disposal methods such as landfilling, indiscriminate dumping, stockpiling, open-air burning, and incineration are commonly used in most developing countries. This is because they are regarded as relatively cheaper and easier methods of getting rid of these tyres. Unfortunately, these methods also present some of the biggest health and environmental challenges associated with waste management. For instance, the bulky nature and the inability to compact the tyres (i.e., 75\% of the space a tyre occupies is void), implies that large land space is required for its disposal (Islam and Nahian, 2016; Rodriguez et al., 2001). Moreover, the void spaces of the tyres when buried underground tend to capture gases such as methane which has a tendency to burn abruptly with a vast explosion. Those indiscriminately dumped on the surface also tend to collect rainwater and serve as good breeding ground for mosquitoes or other bacteria. This causes various harmful diseases to human beings. Those burnt openly or in incinerators also tend to generate harmful emissions/gases such as polyaromatic hydrocarbons (PAHs), benzene, styrene, butadiene, phenol-like substances, $\mathrm{CO}_{2}, \mathrm{CO}, \mathrm{SO}_{x}$, and $\mathrm{NO}_{x}$ which cause excessive damage to human health as well as environmental pollution (Reisman, 1997; Rodriguez et al., 2001; Islam and Nahian, 2016).

Due to the aforementioned challenges faced when these traditional methods are employed coupled with the ever-increasing number of the tyres produced yearly, the race to find alternative approaches is warranted. Conversion of these waste tyres to energy through pyrolysis is one of the technologies that has received much attention recently (Islam and Nahian, 2016; Williams, 2013; Rodriguez, 2001; Williams and Besler, 1995). This is as a result of the dual benefits the technology offers; thus, it gives safer way of reducing waste tyres in the environment as well as utilizing it as a major source of producing alternative fuel to petro/fossil-fuel.

Pyrolysis involves thermal breakdown or decomposition of biomass (e.g., agro waste) and other organic waste materials (such as car tyres and plastics) by heat in the absence of oxygen, which results in the production of char (solid), bio-oil (liquid), and fuel gaseous products (Williams and Besler,1995, Bhatia et al., 1999; Lima et al., 2004). The pyrolysis of biomass has been studied with the ultimate objective of recovering biofuel with a medium-low heating value (Maschio et al., 1992; Barth, 1999; Bridgwater et al., 1999). Production of biofuel via the pyrolytic technologies is currently considered extremely important by several developed and industrialised countries due to; (i) the technology is environmentally friendly since carbon dioxide cycle occurs in combustion process hence contribute to sustainability, (ii) the biofuel could easily be obtained from several biomass sources and (iii) both the biomass source and biofuel are biodegradable (Puppan, 2002; Demirbas, 2006). Notably, the share of biofuel in the automotive fuel market is predicted to grow very fast in the next decade due it its environmental merits (Kim and Dale, 2005; Demirbas and Balat, 2006).

Despite the advancement of energy recovery technologies such as pyrolysis, countries like Ghana still battles with its plastic and tyre waste management. Thus, most of these wastes are either stockpiled, burned in open air or indiscriminately dumped around the communities, hence poses human health threat and environmental pollution. Moreover, work that seeks to explore the effective management of waste tyres generated in Ghana is limited. Therefore, studies that seek to find alternative methods of dealing with these waste tyres in Ghana is very important. In this work, a 
local pyrolytic reactor was designed/fabricated and used in the production of pyrolysis /bio-oil from waste car tyres obtained from some communities in Ghana. Some physicochemical properties of the pyrolysis oil produced were also characterised.

\section{Resources and Methods Used}

\subsection{Materials}

Waste car tyres (Fig. 1) referred as "feedstock" used in this study were collected from local auto mechanic shops from Tarkwa, Ghana. Prior to their usage, the tyres were cleaned thoroughly with water, shredded into pieces and air-dried for $48 \mathrm{~h}$ (Fig. 2).

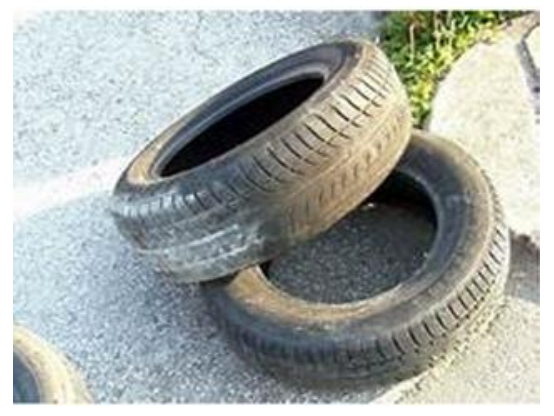

Fig.1 Waste vehicle tyres collected from Tarkwa

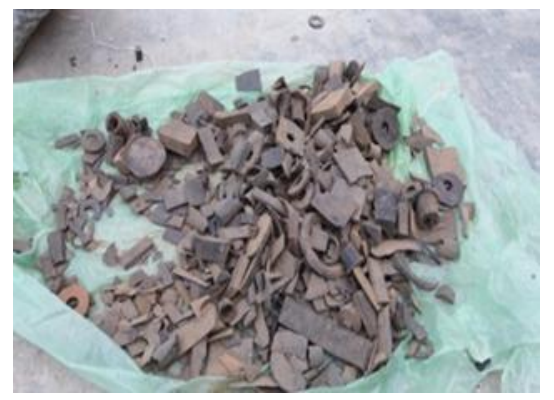

Fig. 2 48-h air-dried, shredded waste vehicle tyres Feedstock

\subsection{Pyrolysis decomposition process}

Fig. 3 shows the pyrolysis reactor that was locally fabricated and used for this research. Generally, 1 $\mathrm{kg}$ of the shredded feedstock was fed into the reactor chamber and externally heated in the absence of oxygen. The volatile components of the feedstock were then captured and condensed into liquid oil through the condensation copper pipes. Residence time for the entire pyrolysis process was $\sim 180$ min but the first drop of the liquid oil into the condensate collection container was observed in the first $60 \mathrm{~min}$ of heating. The process was carried out within the temperature ranges of $450-650^{\circ} \mathrm{C}$. The temperature was measured using UNI-T UT300S IR thermometer. Generally, three products were obtained in the pyrolysis process; tyre pyrolysis oil, pyro gas and char. The tyre pyrolysis oil and char obtained are shown in Fig. 4.

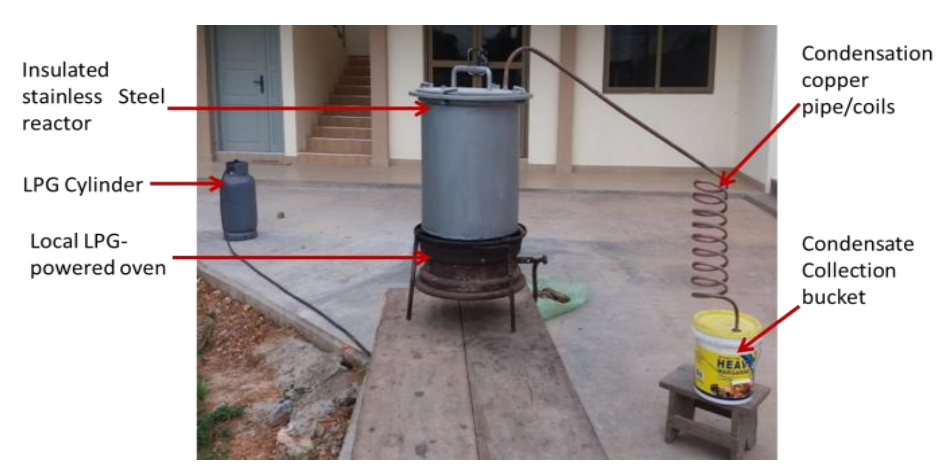

Fig. 3 Locally, Fabricated LPG-Powered Pyrolysis Process Setup

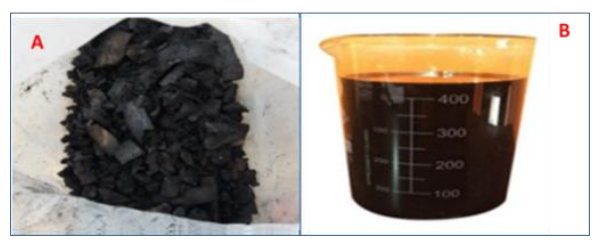

Fig.4 (A) Bio Char and (B) Pyrolysis Oil Produced From Decomposition Process

\subsection{Characterisation of Pyrolysis oil}

The chemical and physical properties of the pyrolysis oil produced were analysed according to the standard methods of the American Society for Testing and Materials (ASTM). The flashpoint was measured using Pensky-Martens closed cup tester according to ASTM D93 method, whilst the water content was determined by ASTM D6751 standard using the volumetric Karl Fischer Titration system. The kinematic viscosity was measured by ASTM D445 standard using automatic kinematic viscometer, sulphur content by ASTM D3177 using Energy Dispersive X-ray Fluorescence Spectrometry and density by the ASTM D4052 method using a digital density meter. The particle counts or solids content of the oil was also determined by ASTM D7579 standard using methanol solid filtration system.

\section{Results and Discussion}

\subsection{Designing and Fabrication Considera- tion of the Pyrolysis Reactor}

Pyrolysis is a complex, thermo-chemical process that decomposes or depolymerises organic material (such as used car tyres and plastic wastes) under oxygen-free conditions (Williams and Besler, 1995; Bhatia et al., 1999; Lima et al., 2004). The products of pyrolysis include oils, gases and char. The process is often carried out in a reactor. Due to 
financial, environmental and social factors, various reactors are designed to suit the users' requirements. In this study, a pyrolytic reactor was designed and fabricated based on the theoretical model as shown in Fig. 5.

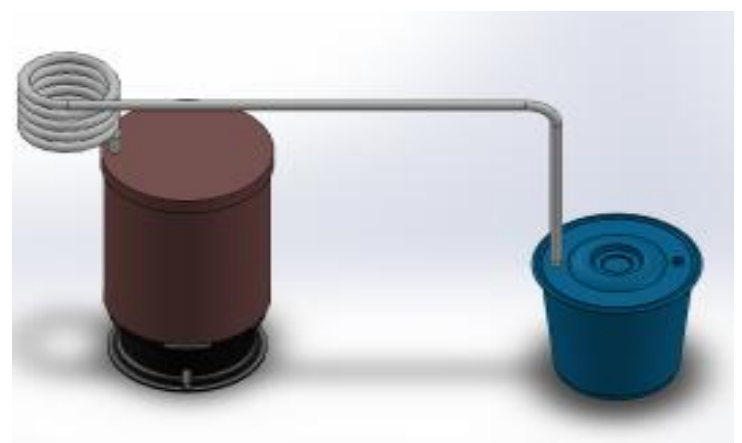

Fig. 5 A 3D Illustration of the Pyrolysis Reactor Used

In designing and fabrication of the pyrolytic reactor, the following assumptions were made; (i) the pyrolysis process occurs within a temperature ranges of $300-700{ }^{\circ} \mathrm{C}$, (ii) the thermal decomposition of a general vehicular tyre generate gases/volatile substances, hence reduces the original weight by $30 \%$ and (iii) the decomposition time of the tyre ranges between $60-240 \mathrm{~min}$ depending on the temperature and reactor's material type. The assumptions were in agreement with reported study by Roy and Darmstdt (1999).

Generally, the pyrolytic reactor was made of stainless steel unit which consisted of insulated, cylindrical chamber of inner diameter of $110 \mathrm{~mm}$, outer diameter of $115 \mathrm{~mm}$ and height of $300 \mathrm{~mm}$. A $1500 \mathrm{~mm}$ long condensation copper pipe and coil was connected to the cylindrical chamber to provide enough retention time for condensation and maximum recovery of the oil. The heating of the reactor was achieved using local LPG powered oven as shown in Fig. 3.

\subsection{Characteristics of the pyrolysis oil}

The pyrolysis oil obtained appeared as thick, darkbrown, single-phase liquid with strong odour at $30^{\circ} \mathrm{C}$ (room temperature). The strong odour may be due to the high aromatic substance (Islam and Beg, 2004). The physical and chemical properties of the oil were further characterised and the results are presented in Tables 1 and 2, respectively.

\subsubsection{Physical Properties of the pyrolysis oil}

Results for physical properties of the pyrolysis oil produced are shown in Table 1 . The kinematic viscosity of the pyrolysis oil at $40{ }^{\circ} \mathrm{C}$ measured was $0.904 \mathrm{cSt}$. The viscosity value of the pyrolysis oil was relatively lower than the standard permissible (both lower and upper limits) values. Notably, the lower kinematic viscosity of the pyrolysis oil could have two effects on its application. Thus, the lower viscosity of the pyrolysis oil may make it easier to pump, atomise and achieve finer droplets when used in fuel injectors as well as easy flow through pipelines, injector nozzles, and orifices (Islam and Beg, 2004; Radovanovic et al., 2000). Contrary, the lower viscosity observed can also lead to easy evaporation of the oil which may result in fuel injection difficulties during pre-heating of the engine (Demirbas, 2007).

The flashpoint of the pyrolysis oil measured was $34.5{ }^{\circ} \mathrm{C}$. Relatively, the flashpoint was significantly lower than the permissible standard lower limit value of $>110{ }^{\circ} \mathrm{C}$. The lower flashpoint $\left(34.5{ }^{\circ} \mathrm{C}\right)$ obtained shows that the pyrolysis oil produced is highly flammable, hence in terms of storage and transportation, a fire-free and highly ventilated environment must always be ensured. Notably, the flashpoint has a little or negligible effect on engine performance but it is important for meeting legislation requirements for fuel transportation and storage (Demirbas, 2009).

The density of the pyrolysis oil produced was 850 $\mathrm{kg} / \mathrm{m}^{3}$ at $15^{\circ} \mathrm{C}$, which was slightly lower than the standard values that ranged between 860 and 900 $\mathrm{kg} / \mathrm{m}^{3}$. Generally, the fuel density affects engine calibration and power, as the fuel mass injected /stroke varies with fuel density (Islam and Beg, 2004; Radovanovic et al., 2000; Demirbas, 2007). Thus, engine combustion and emission are highly linked to fuel density. Notably, an increase in the fuel density results in increased fuel viscosity, which invariably affects the emission of particulates (e.g., $\mathrm{PM}_{2.5}$ ) into the environment (Islam and Beg, 2004; Radovanovic et al., 2000; Islam and Nehian, 2016), as discussed above.

Table 1 Kinematic Viscosity, flash point and density of the pyrolysis oil produced

\begin{tabular}{|l|c|c|}
\hline \multicolumn{1}{|c|}{ Properties } & $\begin{array}{c}\text { Pyrolysis } \\
\text { oil }\end{array}$ & *Standard \\
\hline $\begin{array}{l}\text { viscosity }(\mathrm{cSt}) @ \\
40^{\circ} \mathrm{C}\end{array}$ & 0.904 & $3.5-5$ \\
\hline Flash point $\left({ }^{\circ} \mathrm{C}\right)$ & 34.5 & $>101$ \\
\hline $\begin{array}{l}\text { Density }\left(\mathrm{kg} / \mathrm{m}^{3}\right) \\
\text { @ } 15^{\circ} \mathrm{C}\end{array}$ & 850.6 & $860-900$ \\
\hline
\end{tabular}

*International standard (EN 14214) requirements for biodiesel

\subsubsection{Chemical properties of the pyrolysis oil}

Table 2 shows the sulphur, water and solid/particle contents of the pyrolysis oil produced. The results showed that the pyrolysis oil produced had sulphur content of $4340.0 \mathrm{ppm}$, which was extremely higher than the permissible sulphur content range (3.5 $-5 \mathrm{ppm})$. The higher sulphur content recorded 
for the pyrolysis oil can be linked to the chemical composition of tyre feedstock which contained $\sim 1$ wt.\% sulphur (Evans and Evans, 2006). Generally, the higher sulphur content is not preferable due to the environmental challenges associated with it. Oxidation of sulphur in the oil during combustion may result in the generation of sulphur dioxide $\left(\mathrm{SO}_{2}\right)$ which are often emitted into the environment (Islam and Nehian, 2016). Moreover, some of the $\mathrm{SO}_{2}$ may also condensate or oxidised in the presence of water in the atmosphere to form sulphuric acid haze particles or sulphate aerosol. These sulphate particles form major components of $\mathrm{PM}_{2.5}$. Exposure to the $\mathrm{SO}_{2}$ and $\mathrm{PM}_{2.5}$ are noted to account for negative health issues related to respiratory and heart diseases, globally (Islam and Nehian, 2016). Therefore, the pyrolysis oil produced in this study needs to be treated via desulphurisation process before usage.

The water content of the pyrolysis oil produced was 0.8 vol.\% (8000 ppm). This is relatively higher than the permissible maximum quantity of 0.05 vol.\% (500 ppm). Effectively, the pyrolysis oil produced is expected to exhibit lower energy density and flame temperatures as a result of its higher water content. This may result in poor combustion, high particulate emissions and ignition difficulties, especially when used in diesel engines (Oasmaa et al. 2001; Oasmaa et al., 2005).

The solids content of the pyrolysis oil was $483,495.5 \mathrm{ppm}$. Relatively, the solids content of the pyrolysis oil was extremely higher than the standard value of $2500 \mathrm{ppm}$. Utilisation of the oil with the higher solid content would be detrimental to equipment, particularly injectors in engines and turbine blades (Oasmaa et al. 2001; Oasmaa et al., 2005). Additionally, the higher solid content is also expected to lead to higher particulate emission (Oasmaa et al., 2005), hence further treatment method that reduces the solids content of the oil is required. It is worth mentioning that the waste tyres used were extremely dirty and worn-out, hence the debris/dirt particles may have accounted for the higher solids content of the resultant pyrolysis oil.

Table 2 Sulphur, Water and Solid Contents of the Pyrolysis Oil

\begin{tabular}{|l|l|c|c|}
\hline \multicolumn{2}{|c|}{ Properties } & $\begin{array}{c}\text { Pyrolysis } \\
\text { oil }\end{array}$ & *Standards \\
\hline \multicolumn{2}{|c|}{ Sulphur content (ppm) } & 4340.0 & 50 \\
\hline \multicolumn{2}{|l|}{ Water Content (vol.\%) } & 0.8 & $0.05 \max$ \\
\hline $\begin{array}{l}\text { Sold } \\
\text { content } \\
\text { (Particle } \\
\text { count) }\end{array}$ & $\begin{array}{l}\text { Code } \\
(\mu \mathrm{m}) \\
(4 / 6 / 14)\end{array}$ & $483,495.5$ & 2,500 \\
\cline { 2 - 4 } & $26 / 24 / 18$ & $18 / 16 / 13$ \\
\hline
\end{tabular}

\section{Conclusions}

In this study, a pyrolysis reactor was successfully designed and fabricated for the decomposition of the waste vehicle tyres. The pyrolysis oil produced was a single-phase liquid (with no separation between the aqueous and organic phases) with relatively lower density $\left(850.6 \mathrm{~kg} / \mathrm{m}^{3}\right)\left(\right.$ at $\left.15^{\circ} \mathrm{C}\right)$, flashpoint $\left(34.5{ }^{\circ} \mathrm{C}\right)$ and viscosity $(0.904 \mathrm{cSt})$. However, the water $(0.8$ vol.\%), solids $(483,495.5$ ppm) and sulphur (4340.0 ppm) contents were also relatively higher than international standards for diesel. This means that using the pyrolysis oil as a fuel would require preliminary treatments such as desulphurisation, decanting, centrifugation and filtration. The treated pyrolysis oil could be used alone or blended with other diesel fuels to achieve maximum performance. For instance, the blending is expected to reduce the viscosity of the resulting blend which would consequently improve the atomisation that would ensure a complete burnout of the fuel. Moreover, tyre-derived pyrolysis oils can be considered a valuable component for use with conventional fuels based on their fuel properties.

\section{Acknowledgements}

The technical supports received from the Departments of Environmental and Safety Engineering and Minerals Engineering, of the University of Mines and Technology, Tarkwa, Ghana, are highly acknowledged. The laboratory support from Total Ghana Ltd., Iduapriem site, for the analyses of the properties of the pyrolysis oil produced is much appreciated.

\section{References}

Abbaszaadeh, A., Ghobadian, B., Omidkhah, M. R. and Najafi, G. (2012), "Current biodiesel production technologies: A comparative review", Energy Conversion and Management, Vol. 63, pp. 138-148.

Barth, T. (1999), "Similarities and differences in hydrous pyrolysis and source rocks", Organic Geochemistry, Vol. 30, pp. 1495-1507.

Bridgwater, A. V., Meier, D., and Radlein, D. (1999), "An overview of fast pyrolysis of biomass", Organic Geochemistry, Vol. 30, pp. 1479-1493.

Carriquiry, M.A., Du, X. and Timilsina, G.R. (2011), "Second generation biofuels: Economics and policies". Energy Policy, Vol. 39, pp. 4222-4234.

Cheng, J. J. and Timilsina, G. R. (2011), "Status and barriers of advanced biofuel technologies: A review", Renewable Energy, Vol. 36, pp. 3541-3549. 
Demirbas, A. (2006), "Biodiesel production via non-catalytic SCF method and biodiesel fuel characteristics", Energy Conversion and Management, Vol. 47, pp. 2271-2282.

Demirbas, A. (2007), "The influence of temperature on the yields of compounds existing in bio-oils obtained from biomass samples via pyrolysis", Fuel Processing Technology, Vol. 88, pp. 591-597.

Demirbas, A. (2009), "Progress and recent trends in biodiesel fuels", Energy Conversion and Management, Vol. 50, pp. 14-34.

Demirbas, M. F. and Balat, M. (2006), Recent advances on the production and utilization trends of biofuels: a global perspective", Energy Conversion and Management, Vol. 47, pp. 2371-2381.

Evans, A. and Evans, R. (2006.), "The composition of a tyre: typical components", The Waste \& Resources Action Programme, pp. 5.

Frank, A. F. (2005), "Oil Empire: Visions of Prosperity in Austrian Galicia", Harvard Historical Studies, Harvard University Press, Cambridge, MA, USA, 366 pp.

Galvagno, S. and Cornacchia, G. (2002), "Pyrolysis process for the treatment of scrap tyres: preliminary experimental results", Waste Management, Vol. 22, pp. 917-923.

Hamelinck, C. and Faaij, A.P.C. (2006), "Outlook for advanced biofuels”, Energy Policy, Vol. 34, pp. 3268-3283.

Islam, M. N. (2004), "Fixed bed pyrolysis of scrap tyre for liquid fuel production", International Energy Journal, Vol. 5, No. 1, pp.11-18.

Islam, M. N. and Beg, M. R. A. (2004), "The fuel properties of pyrolysis liquid derived from urban solid wastes in Bangladesh", Bioresource Technology, Vol. 92, pp.181-186.

Islam, M.N. and Nahian, M. R. (2016), "Improvement of Waste Tire Pyrolysis Oil and Performance Test with Diesel in CI Engine", Journal of Renewable Energy, Vol. 8.

Izadi, P. and Rahimnejad, M. (2014), "Simultaneous electricity generation and sulfide removal via a dual chamber microbial fuel cell", Biofuel Research Journal, Vol.1, No. 1, pp. 3438.

Kartha, S. and Larson, E. D. (2000), Bioenergy primer: modernised biomass energy for sustainable development, Technical Report UN Sales Number E.00.III.B.6, United Nations Development Programme, Vol. 1, United Nations Plaza, New York, NY 10017, 133 pp.

Kim, S. and Dale, B. E. (2005), "Life cycle assessment of various cropping systems utilized for producing: bioethanol and biodiesel", Biomass Bioenergy, Vol. 29, pp. 426-439.

Lima, D. G., Soares, V. C. D., Ribeiro, E. B., Carvalho, D.A., Cardoso, E. C. V., Rassi, F.C., Mundim, K.C., Rubim, J.C., Suarez, P. A.Z.
(2004), "Diesel-like fuel obtained by pyrolysis of vegetable oils", Journal of Analytical and Applied Pyrolysis, Vol. 71, pp. 987-996.

Luque, R., Herrero-Davila, L., Campelo, J.M., Clark, J.H., Hidalgo, J., Luna, D., Marinas, J.M. and Romero, A.A. (2008), "Biofuels: A Technological perspective", Energy Environ. Sci., Vol. 1, pp. 542-564.

Maschio, G., Koufopanos, C., Lucchesi, A. (1992), "Pyrolysis- A promising route for biomass utilization", Bioresource Technology, Vol. 42, pp. 219-231.

Mastral, A. M., Murillo, R., Callen, M. S. and Garcia, T. (2000), "Optimisation of scrap automotive tyres recycling into valuable liquid fuels", Resources Conservation and Recycling, Vol. 29, No. 4, pp. 263-272, 2000.

Mohammadi, P., Tabatabaei, M., Nikbakht, A. M. and Esmaeli, Z. (2014), "Improvement of the cold flow characteristics of biodiesel containing dissolved polymer wastes using acetone", Biofuel Research Journal, Vol. 1, No. 1, pp. 2629.

Oasmaa, A. Peacocke, Gust, S., Meier, D and McLellan, R, (2005), "Norms and Standards for Pyrolysis Liquids. End-User Requirements and Specifications", Energy and Fuels, Vol. 19, No. 5, pp. 2155-2163.

Oasmaa, A., Kytö, M. and Sipilä, K. (2008), "Pyrolysis Liquid Combustion Tests in an Industrial Boiler", Progress in Thermochemical Biomass Conversion, Bridgwater, A. (ed.), Blackwell Science: Oxford, U. K., Vol. 2, pp 1468-1481.

Peralta-Yahya, P. P., Zhang, F., Del Cardayre, S. B. and Keasling, J. D. (2012), "Microbial engineering for the production of advanced biofuels", Nature, Vol. 488, pp. 320-328.

Puppan, D. (2002), "Environmental evaluation of biofuels", Periodica Polytechnica Social Management Sciences, Vol. 10, pp. 95-116.

Radovanovic, M., Venderbosch, R. H., Prins, W. and van Swaaij, W. P. M. (2000). "Some remarks on the viscosity measurement of pyrolysis liquids", Biomass Bioenergy, Vol. 18, pp. 209-222.

Reisman, J. I. (1997), “Air emissions from scrap tire combustion” Technical Report, EPA-600/R, pp. 97-115.

Rodriguez, I. M., Laresgoiti, M. F., Cabrero, M. A., Torres, A., Chom'on, M. J. and Caballero, B.M. (2001), "Pyrolysis of scrap tyres", Fuel Processing Technology, Vol. 72, No. 1, pp. 922.

Roy, C. and Darmstdt, H. (1999), "The Vacuum pyrolysis of used tyres: End-uses for oil and carbon black products", Journal of Analytical and Applied Pyrolysis, Vol. 51, No. 1-2, pp. 201-221. 
Sharma, Y. C., Singh, B. and Upadhyay, S. N. (2008), "Advancements in development and characterization of biodiesel: A review", Fuel, Vol. 87, pp. 2355-2373.

Swain, S. K. (2013), "Recycling of Waste Tyres: A Possible Option for Deriving Energy", Unpublished B.Tech Thesis, National Institute of Technology, Rourkela, India, p. 28.

Tabatabaei, M., Tohidfar, M., Salehi Jouzani, G. H., Safarnejad, M. and Pazouki, M. (2011), "Biodiesel production from genetically engineered microalgae: Future of bioenergy in Iran", Renewable and Sustainable Energy Review, Vol. 15, pp. 1918-1927.

Timilsina, G. R. and Shrestha, A. (2011), "How much hope should we have for biofuels?", Energy, Vol. 36, pp. 2055-2069.

Williams, P. T. and Besler, S. (1995), "Pyrolysisthermogravimetric analysis of tyres and tyre components", Fuel, Vol. 74, No. 9, pp. 12771283.

Williams, P. T. (2013), "Pyrolysis of waste tyres: A review", Waste Management, Vol. 33, No. 8, pp.1714-1728.

\section{Authors}

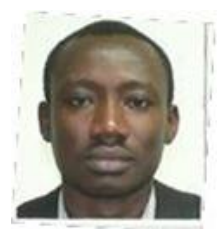

I. Quaicoe is a Senior lecturer at the University of Mines and Technology, Tarkwa, Ghana. He holds BSc and PhD degrees in Minerals and Materials Engineering from the University of Mines and Technology, Tarkwa and University of South Australia, Australia, respectively. His current research areas include Wasteto-Energy concepts, Geometallurgy, Hydrometallurgy, Environmental and Safety Management, Local Economic and Social Development, Mine waste management, Colloid Science and Rheology, Waste water treatment, Development Minerals and Artisanal and Small-Scale Mining and Processing.

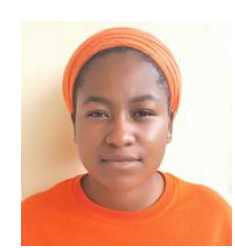

A. Affo Souleymane Ayisha Affo Souleymane works with Twellium Industrial Company as an Environmental, Health and Safety Officer. She holds BSc. Environmental and Safety Engineering from the University of Mines and Technology in Ghana. Her current research areas include Industrial Solid Waste Management, Environmental Management, Waste Water Treatment and Hazardous Waste Management

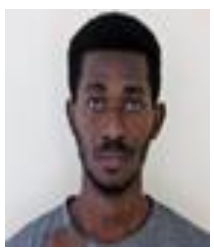

S. K. Kyeremeh is a graduate from the University of Mines and Technology (UMaT), Tarkwa. He holds a BSc (Hons) degree in Environmental and Safety Engineering. $\mathrm{He}$ is currently an Environmental Consultant at Nature Solutions Limited. His research interests include Mine Wastewater treatment, Environmental Sampling and Monitoring, Waste Management and Environmental and Safety Management. He is a member of Ghana Institute of Safety and Environmental Professionals and Red Cross Society.

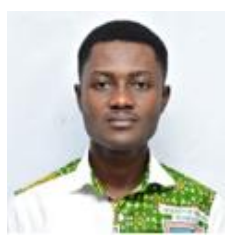

H. Appiah-Twum is an Environmental and Safety Engineering graduate from the University of Mines and Technology UMaT), Tarkwa, Ghana. He has research interest in Environmental Management, Hazardous Waste Management, Air Pollution, Climate Change, Waste Water Treatment, and Risk Assessment.

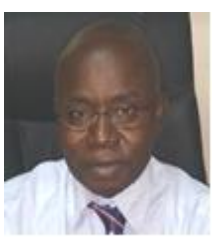

S. A. Ndur is Associate Professor of Environmental and Safety Engineering at the University of Mines and Technology, Tarkwa. He obtained his PhD (Environmental Geochemistry) from New Mexico Institute of Mining and Technology, USA in 2007 and MSc (Petrochemical Engineering) from Moscow Institute of Oil and Gas, CIS. He is a member of Society of Environmental Geochemistry and Health (SEGH), and International Association of Impact Assessments (IAIA). His research areas are Environmental Pollution and Control, Mine Waste Characterisation and Management, Arsenic Sequestration, and Water Quality Issues. 